\title{
Groping in the Dark with the "Non-Places" BRICS: Geopolitics of the Emergence of an Empire or States Racing to the Bottom?
}

\author{
Professor Johannes Tsheola
}

\author{
Department of Development Planning \& Management, University of Limpopo, South Africa \\ johannes.tsheola@ul.ac.za
}

\author{
Doi:10.5901/mjss.2014.v5n25p187
}

\section{Abstract}

Theorization of regionalism is yet to resolve the question of the appropriateness of amalgamation versus pluralism jurisdiction. The formation of the BRICs in 2009, and the inclusion of South Africa in the 2011 BRICS in complete disregard of the Goldman Sachs' foundational conceptual modelling and forecasting of the original acronym (Brazil, Russia, India and China), has tacitly reinvented the philosophical and conceptual questioning of globalism and regionalism. The BRICS does not fit notions of amalgamation or pluralism regionalism, thereby accentuating the cracks of the explanatory power in analytical concepts of market integrationism in global geopolitics and international relations. Whereas China and Russia are not perfect fit for the concept of emerging economies, the business, financial and economic framing of the set is grounded in an oxymoron of the calibre of development, globalization and regionalism. The latter two have appeared to provide convenient flags under which all ships could sail; hence, the emergence of the BRICs, BRICS, Nafta, Mercosur, Next-11, BRICSAM and IBSA. Given historical matrices of coloniality in global geopolitics and international relations, Russia and, perhaps, China could be harbouring selfinterests relating to cultural, historical and ideological assimilation within the set. To this extent, the BRICS set's regionalism should construed as another oxymoron wherein member states joined "non-places" that are "groping in the dark" within global geopolitics and international relations. Nuance notions of "empires" provide useful insights to understanding the motives underlying the BRICS set. This article aims to determine if the BRICS set signifies the emergence of contemporary empires with "civilizing" missions or if it is a manifestation of states racing to the bottom. The article concludes that the BRICS is a deeply complex and conflicted set that involves attempts at both externally-driven and inward-oriented management of international geopolitics through "civilizing" missions and/or "non-places" regionalism of states racing to the bottom.

Keywords: Globalism; Regionalism; Global Geopolitics; Management of International Relations; Market Integration; BRICS set

\section{Introduction}

Disguised as fundamental universalistic truths, neoliberal globalism, market integration regionalism and the European Union (EU) model have been touted as benign and inescapable options for the management of contemporary global geopolitics and international relations. Hence, emerging economies have been urged to adopt regionalism arrangements as suboptimal options for transition towards the optimal multilateral openness and globalism. Based on the customs union theory, the EU has been construed as the ideal model of amalgamation of jurisdiction that would deliver collective prosperity and development. To this extent, Todaro (1997, p.421) advises that emerging economies need to "look outward but in a different direction (towards trade and cooperation with other LDCs) and inward towards each other as members of a group of nations trying to integrate their economies and coordinate their joint development strategies in an effort to achieve greater collective self-sufficiency". However, this regionalism thinking has flagrantly circumvented the preconditions for complementarity of economies as well as production and trade structures. The agglomerations of the emerging economies in the Next-11 (N-11) and the BRICS are framed in the hope of shaping global geopolitics and management of international trade relations. Whereas the BRICS describes itself as "a group of leading emerging economies playing a key role in the world development platforms" (BRICS, 2013, vi), its performance on the global stage as a set does not seem to affirm the self-description as "strong emerging states", economically and politically, except for Russia.

Additionally, there are no macro-economic basis, at least on the face of the data analysed in this article, to justify why the original BRICs set was heralded as one of "the growth centres of the future with the potential to stimulate increased demand for a wide range of commodities" (Cairns \& Meilke, 2012, n.p). Evidently, the BRICS set consists of disparate states that cannot even be generalised as emerging markets or "strong emerging states". Apparently, the ongoing practice of the BRICS has nothing, other than the usurpation of the acronym, to do with the 2001 Goldman 
Sachs modelling. The June 2009 BRICs summit itself had revealed the depth fissures of the set in global geopolitics and discrepancies in their management of international relations (Cooper, 2009; Tandon \& Shome, 2009). The hope that the BRICS set could in 2050 dominate the global economy, relative to the G-6 of France, Germany, Italy, Japan, United Kingdom and the United States (Wilson \& Purushothaman, 2003; Wilson, Kelston \& Ahmed, 2010), must be dismissed as unrealistic. Besides, recent events in global geopolitics and management of international relations demonstrate that the BRICS set is neither the North Atlantic Treaty Organisation (NATO) nor EU nor the G-6 or G-7 or G-20 of the world. Five of the ten guiding principles (centrality of multilateralism on global issues; mutual respect for one another's choice of the development path; openness; non-bloc nature; and, neutrality with regard to third parties (BRICS, 2013)) are such that the BRICS set would largely operate as a pluralistic jurisdiction and, therefore, a "non-places" regionalism in the global geopolitics and management of international relations. Indeed, the BRICS set is presently famous as an acronym but extraordinarily weak in global geopolitics and management of international relations.

Rather than qualitatively alter the traditional global patterns of economics and politics, the BRICS set appears to be "striking for its declaratory than operational force" because the member states are more marked for their differences, dissimilar geographic locations, unique cultural and diverse historical contexts, rather than collective identities (Cooper, 2009 , n.p.). For these reasons, the Standard and Poor Report does not recognize the BRICS set as a regional grouping (Tandom \& Shome, 2009). The BRICS set's hope of shaping the global geopolitics and management of international relations as a set is more sentimental than a potent operational pragmatic force. According to Cooper $(2009$, n.p),

"In many ways, nevertheless, the BRICs are more interesting for their differences than their similarities. Brazil and India are robust democracies. Russia is a managed democracy. China is a one party state. India has a fast rising population. Russia is in serious demographic trouble with a sharply reduced life expectancy. Brazil and Russia are resource rich. India and China are resource dependent".

The business, financial and economic rationale of the BRICS set would not hold under these circumstances. It is impossible to ignore the Financial Times' (08 February 2006) observation to the effect that the "BRICs has joined nonplaces such as Emea, Asean and Nafta in the acronym-crazed geography of international management"; and, it stands as a nominal "rudimentary geographical trade configurations" (Olivier, 2001, p.43) in contemporary global geopolitics. This article holds that the BRICS set will remain a disparate and non-cohesive grouping, both economically and politically, because member states have opted for pluralistic jurisdiction, non-unison global action and non-conformity to "the body of ideas, values and concrete objectives" (Grant \& Soderbaum, 2003, p.7). For these reasons, the BRICS set has to be construed as nominal rudimentary "non-regionalism" grouping and "inexact" imitation, deliberate or accidental, in the management of contemporary global geopolitics and international relations.

\section{Globalism versus Regionalism and the Goldman Sachs Conception of BRICs}

Regionalism remains a complex and unresolved conceptual framing that had relied heavily on the success of the European Union (EU). According to Grant \& Soderbaum (2003, p.7), regionalism describes "the body of ideas, values and concrete objectives that are aimed at transforming a geographical area into a clearly identified regional space". Notwithstanding the complex and multifaceted processes as well as diverse actors in such a space (Lee 2003), regionalism implies that member states would act in unison in their management of international geopolitics, notwithstanding their uniqueness in cultures, histories and ideologies. More importantly, the ideal regional space for regionalism is contiguous (Ramutsindela, 2005, 2011). Intricately connected with theories of development such as modernization and dependency, regionalism was accepted among emerging economies as a counterforce against neoliberal globalization (Gibb, 2009). Post-1950s, the regionalism discourse was captivated by four approaches that were unambiguously grounded in specific development paradigms. Inevitably, the regionalism discourse was caught in the state-market paralysis and dominated by populist development paradigms denoted growth-focused, pro-poor growth, green-growth and resilient-growth (Glemarec \& Puppim de Oliviera, 2012).

The four approaches to regionalism include development cooperation, market integration, "open" and "new" regionalism (Hettne, 1999; Oden, 1999; Grant \& Soderbaum, 2003; Iheduru, 2003; Fawcett, 2005; Gibb, 2009; Bachmann \& Sidaway, 2010). Given the predominance of neo-libertarian globalization, the modernist market-led integration approach became hegemonic in its calls for liberalization and abolishment of discrimination between member states (Todaro, 2007; Mistry, 2000; Fawcett, 2005; Gibb, 2009). The triumphalism of neoliberal globalism meant that the market integration regionalism approach too would become hegemonic; and, open regionalism emerged in the early 1990s as an aggressive variant of the market integration approach. Open regionalism, therefore, signified a symbolic return to "neoclassical economic agenda" and modernization development thinking. The underlying motive of open regionalism appears to have been to rejuvenate multilateral trade liberalisation and ultimate "integration" of states and 
constellations thereof into the world-economy as propelled under the World Trade Organization (WTO) (Gibb, 2009). With the ascendency of neoliberal globalization, open regionalism was designed to undermine conventional wisdom on regional integration in the hope of ensuring that regional arrangements would become suboptimal solutions and steps towards the ultimate optimal multilateral neoliberal globalization, as provided for in the WTO's Most Favoured Nation Principle (MFN). "New" regionalism thinking has remained scarcely developed and it continues to be in its infancy because it emerged at the beginning of the $21^{\text {st }}$ century, notwithstanding some forceful writings (Hettne, 1999; Oden, 1999; Boas, 2003; Grant \& Soderbaum, 2003; Iheduru, 2003; Lee, 2003; Ramutsindela, 2005; Gibb, 2009). The key distinguishing feature of "new" regionalism is in its rejection of the state-centric model of regional integration (Hettne, 1999; Oden, 1999; Boas, 2003; Grant \& Soderbaum, 2003; Iheduru, 2003; Lee, 2003; Ramutsindela, 2005; Gibb, 2009). This rejection of state-centric notion of regionalism is justifiable because in practice there are multiple regional and global actors (Ramutsindela, 2005). As Simon (2010) puts it, marked progress in regionalism is made by commercialized nonstate actors because they are capable of operating relatively freely, devoid of official policy hindrances. Therefore, "new" regionalism transcends conventional formal state-centric thinking on regionalism, because it is inherently restrictive, narrow and misleading, especially now that the most successful regional and global actors have been private institutions, by integrating post-structuralism and postmodernism (Boas, 2003; Grant \& Soderbaum, 2003; Iheduru, 2003; Gibb, 2009; Simon, 2010).

According to Gibb (2009, p.714), "new" regionalism's rejection of the conventional state-centric model of regionalism as "neorealism", "neoliberal institutionalism" and "neoliberal inter-governmentalism" is itself imbued with conceptual drawbacks of "a narrow Westphalian understanding and interpretation of the state". Also, the use of the descriptor "new" is conceptually problematic because it is open to "varied assumptions and interpretations of what is 'old' and 'new"' for most emerging economies (Ramutsindela, 2005, p.107). Reading from the continued preoccupation with neoliberalism and marketization, Gibb (2009, p.706) asserts that contemporary regionalism discourse is preoccupied with "a set of ill-defined development objectives", exclusively "centred on market integration and modernity". Gibb (2009, pp.714, 715) asserts that "states should continue to form the focus of attention" in the theorization of regionalism; however, he dismisses the notion that "states co-operate" over regionalism because "it is in their best interests to do so", as uncritical and simplistic. Gibb (2009, p.708) states that as "state-centric and elite-driven phenomena, focused on interstate and inter-governmental relations", market regionalism portrays integration as a process that "generates a form of economic determinism that will eventually bind sovereign states into ever-closer union". Proponents of market integration believe that unfettered markets encourage economic agglomeration and polarization (Boas, 2003; Gibb, 2007). However, such state-centric or "elite-led" regionalism involves a requirement for concessions of state authority, power and sovereignty to the regional entity (Sidaway, 1998, 2002; Boas, 2003; Taylor, 2005; Gibb, 2009; Bachmann \& Sidaway, 2010). From emerging economies' perspective, the exercise of state sovereignty is inextricably intertwined with regionalism; and, in practice notions of regionalism have been exploited for rhetorical purposes, commitments and configuration of sovereignty without ceding authority to the regional entity (Bachmann \& Sidaway, 2010). The nomenclature of "nominal regionalism" appears to be the most befitting for the BRICS set; and, the establishment of the Bank does not help because it appears to suggest that the set has no global economic or political agenda other than being a vehicle for "mobilizing resources and asserting state sovereignty" (Bachmann \& Sidaway, 2010, p.1). Recent global events demonstrate that the BRICS is a virtual absence in the politics about Russia.

Ironically, the BRICS set appears to be an attempt at regionalism that functions to inscribe state powers wherein the state elite exercises and reasserts sovereignty through the regional entity (Sidaway, 1998). To this extent, Sidaway (1998, p.571) rejects the thinking that regionalism entails state concessions of sovereignty and power; instead, emerging economies appear to engage in regionalism to establish and consolidate a "set of processes by which sovereignty is confirmed". Emerging economies adopt regionalism, therefore, as a strategy for demonstrating and bolstering "sovereignty through participating in practices only open to state actors" (Bachmann \& Sidaway, 2010, p.4). In general, there has been a suspicion that emerging economies, especially those in Africa, have accepted regionalism as "a fundraising strategy" (Ramutsindela, 2010, p.93), because it is a "non-threatening" form of attaining legitimacy without imposing the requirements for democracy or sharing of sovereignty or genuine development (Sidaway \& Gibb, 1998; Sidaway, 2002; Boas, 2003; Fawcett, 2005; Gibb, 2009; Ramutsindela, 2009). To be precise, the market integration regionalism approach gained global prominence through traditional customs union theory, infusing therefore neoclassical economics and international trade theory, modernist assumptions and values, the concepts of customs union, trade creation and trade diversion, and free trade with notions of "predetermined and inevitability of modernity" (Gibb, 2009, p.708). However, the neoclassical approach to regionalism portrays free global trade as the key for enhancing national economic growth of trading partners (Todaro, 1997; Lee, 2003; Olanrewaju, 2007). To this extent, intra-regional dynamics are thought to promote harmonisation of policies and exploitation of comparative advantage for exportation and 
establishment of free movement of factors of production (Todaro, 1997; Olanrewaju, 2007; Gibb, 2009). The market integration regionalism approach, just the modernization theory, was presented as fundamentalist and universalist truths, with assumed applicability across the world that was fuelled by the success stories of the EU. Regionalism discourse and practice among emerging economies was primarily driven through the acceptance of the EU model as globally relevant and applicable (Gibb, 2007, 2009; Olanrewaju, 2007). Despite the evident prescription of Eurocentric values for regionalism transposition among emerging economies, failure anywhere else came to be blamed on the victim (Simon, 1998, 2010; Sidaway, 2002; Taylor, 2005; Olanrewaju, 2007; Bachman \& Sidaway, 2010; Ramutsindela, 2010). To be precise, as Gibb (2007, p.433) observes, the success and failure of regionalism became a function of acceptance, or lack thereof, of "rules-based and legally enforceable regional governance structure, together with sharing of sovereignty" in accordance with the EU model. Failure was exclusively explained through states' alleged reluctance to cede and share sovereignty.

Market integrationism prescribes a six-step "deterministically linear" hierarchical inevitability of regionalism and "progression of increasingly more complex integrative steps towards full economic and political union" (Gibb, 2009, p.707). The six-step regional progression commences with preferential trade, then free trade association, customs union, common market, and economic union, to political union (Todaro, 1997; Lee, 2003; Gibb, 2009). Preferential trade involves partial removal of internal quotas and tariffs; and, free trade association allow for complete elimination of such internal quotas and tariffs (Todaro, 1997; Lee, 2003; Gibbs, 2009).Customs union relates to the establishment of a common external customs tariff; and, the common market provides for free movement of commodities, labour, capital and services (Todaro, 1997; Lee, 2003; Gibbs, 2009).On its part, economic union harmonises economic policies and development of the regional institutions; and, political union allows for unification of politics and power (Todaro, 1997; Lee, 2003; Gibbs, 2009). Notwithstanding the contestations of the conception of regionalism, two issues stand out clearly as critical for its practice; and, these are: states' capacity to share sovereignty at the regional scale, and the potential to imitate the EU model. A brief comparison of amalgamation and pluralistic regional jurisdiction is necessary to shed light into the "inexact" imitations of the EU. To-date, there is no regional integration arrangement that is an "exact" imitation of the EU model, notwithstanding the innumerable attempts across the world.

Accurately, Simon (1998, p.6, 2010, p.97) asks is a region is to be envisioned in singular terms of "a coherent or uniformity of approach and dynamic", or if it should be considered as "more diverse, pluralistic development processes which permit divergent as well as convergent futures". Under pluralistic regionalism, participating states retain separate jurisdiction of their activities whereas there is collective jurisdiction by supra-national institution in amalgamation (Davies, 1996; Olivier, 2001; Njinkeu \& Fosso, 2006; Olanrewaju, 2007). Unlike amalgamation, pluralistic regionalism is a virtual "no regionalism" option (Davies, 1996; Olivier, 2001; Njinkeu \& Fosso, 2006; Olanrewaju, 2007). With the same underlying motive as open regionalism, pluralism allows for the realization of the MFN principle by making it impossible to create a protective common external tariff (CET) against third-parties (Davies, 1996; Olanrewaju, 2007). As already indicated, any intra-region preference becomes a temporary passing phase and process of mutual regionalism which strengths and extends generalised and significantly lower CET (Oyejide, 2000; Olanrewaju, 2007). As Olanrewaju (2007, p.6) puts it, the MFN principle, like pluralism regionalism, "actually means non-discrimination", equal treatment of "virtually all countries". According to the WTO, regional arrangements that do not conform to the MFN principle are only acceptable if "the tariff applying to external parties is not, on the whole, higher than the tariffs previously in force" (Davies, 1996, p.34). The absence of a regional protective CET under pluralism (Oden, 1999; Oyejide, 2000; Grant \& Soderbaum, 2003; Lee, 2003; Olanrewaju, 2007) implies that the primary motive for such regionalism for the regional set does not seek "to maximise intra-regional trade rather than trading with third-party countries at the expense of the region" (Ralinala, 2004, p.131). To this extent, pluralism would not create "sufficiently large market size to generate lower production cost that might enable the region to compete better with the rest of the world" as an integrated regional unit (Oyejide, 2000, p.5).

Evidently, the BRICS does not fit the conventional traditional customs union logic; instead, it could be either a deliberate or accidental "inexact" imitation of the EU model. To this extent, the BRICS set can be accurately characterized as "nominal regionalism", designed for exercise of state sovereignty and as an instrument for fund-raising. Perhaps, member states may be in the BRICS for diverse and, possibly, contradictory purposes and motives. Five of the tem foundational principles of the BRICS set show that the grouping is not designed to enforce amalgamation of jurisdiction; and, it is wishful thinking to expect participating states to cede sovereignty to a supra-regional institution, inclusive of the new BRICS Bank. Also, the BRICS set has not been a global actor of note on any of the recent economic and political developments; and, the set does not even appear to be an "inexact" imitation of the existing "non-places" in the management of international geopolitics, such as the G-77, G-20, G-8(now, G-7) and G-6. To this extent, the BRICS set is not a version of any of the innumerable "inexact" imitations of the EU, such as North American Free Trade Agreement (Nafta), Mercosur, African Union (AU) or even the geographically non-contiguous North Atlantic Treaty Organization 
(NATO). Despite being geographically fragmented "non-regionalism", the BRICS set's foundational principles are destined to condone the enforcement of the MFN principle and global openness. On the international stage, the BRICS set is increasingly appearing to be an economic trade and political irrelevance, as a grouping. Importantly, for the BRICS set to be globally consequential by shaping the economic and political agendas, it is imperative for the constellation to meet some fundamental requirements.

\section{Globalism and Regionalism Oxymorons for the BRICS: Business, Financial and Economic Framing}

There is overt quixotic promise in the notions of globalism and regionalism for the BRICS; perhaps, that would explain the origin of the notion of this set and its acronym from Goldman Sachs in 2001. The original framing included the so-called emerging economies of Brazil, Russia, India and China in BRICs on account of their large population sizes (Wilson \& Purushothaman, 2003; Wilson, Kelston \& Ahmed, 2010; Cairns \& Meilke, 2012). The 2012 population statistics of the set demonstrates unequivocally that it was reasonable to exclude South Africa from the original conception in 2001 (Figure 1). The populations of Brazil and Russia are miniscule relative to that for India and China; and, South Africa's is untenably incomparable. If the large population sizes are key to the BRICS set becoming "increasingly important in the world economy" (Haq \& Meilke, 2009a, p.2; 2009b, p.2), as the Goldman Sachs conception would have it, then member states' population sizes should have been at least comparable. Even if South Africa were to be excluded from the set, Brazil and Russia have population sizes that are far below those for India and China. The founding logic would still be untenable, given the population size realities of the set.

Figure 1: The BRICS Set Population Statistics (Millions), 2010-2012

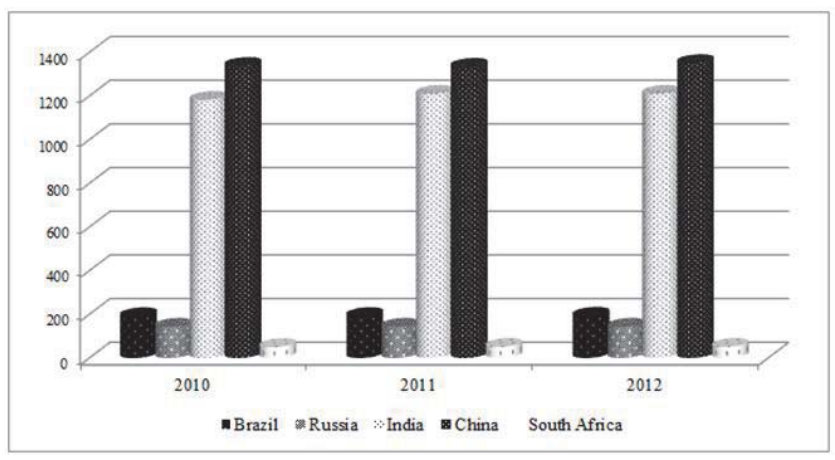

Source: BRICS (2013)

Whereas commitment to capitalist economic relations is, for emerging economies, increasingly criticised as "a naïve understanding of what development entails" or ignorance of the experiences of the global South or an outright "mental subjugation to a Western vision" (Mkandawire, 2011, p.8-9), neoliberal globalism is fundamental to the motivation of the original BRICs set of Brazil, Russia, India and China. The primary hope was that these member states would grow the global demand of commodities, goods and services, especially from the industrialized economies, largely by adherence to economic freedom policies. This notion portrayed the benefits of globalism as though it were an end in itself. The global prominence of the BRICS set did not arise from the power capabilities of these so-called emerging economies, which are sometimes self-described as "big emerging states" (Cooper, 2009; Haq \& Meilke, 2009a, 2009b; Tandon \& Shome, 2009; Wilson, Kelston \& Ahmed, 2010; Bell, 2011; Cairns \& Meilke, 2012).

The combination of large populations and the four core macro-economic (macro stability, institutions, openness and education) pre-conditions for high growth, as forecast by the Goldman Sachs (Bell, 2011, p.19), should raise eyebrows. The promise of high economic growth has always been promised to the so-called emerging economies, on the pre-condition that they adopt structural reforms. But the apparent imitation, deliberately and/or accidentally "inexact", is yet to deliver prosperity for the poor countries. In this context, the BRICS set could be, if we could draw phraseologies from Mkandawire (2011, p.7), the afterthought of the solipsistic bellicose oxymoron of global capitalist economic relations of development and "the propensity and possibility of emulation" associated with "common humanity and intelligibility" that defines externalities of impostures of "historical experiences and social needs" in international relations. Hence, Russia and China are included in the 2001 Goldman Sachs' framing of the BRICs when none of them is an "emerging economy". 
Besides, Russia was until the Ukraine war and international conflict embraced as a member of the G-8 of rich nations. In this context, suspicion of imperial motives underlying the framing of the BRICs and the later inclusion of the "non-fit" South Africa would remain hard to dispel. Indeed, the 2011/2012 GDP and per capita GDP of the BRICS set demonstrate that these countries cannot be tenably classed together as "emerging economies" (Figure 2).

Figure 2: BRICS Set GDP and per Capita GDP at Current Prices, 2011/2012

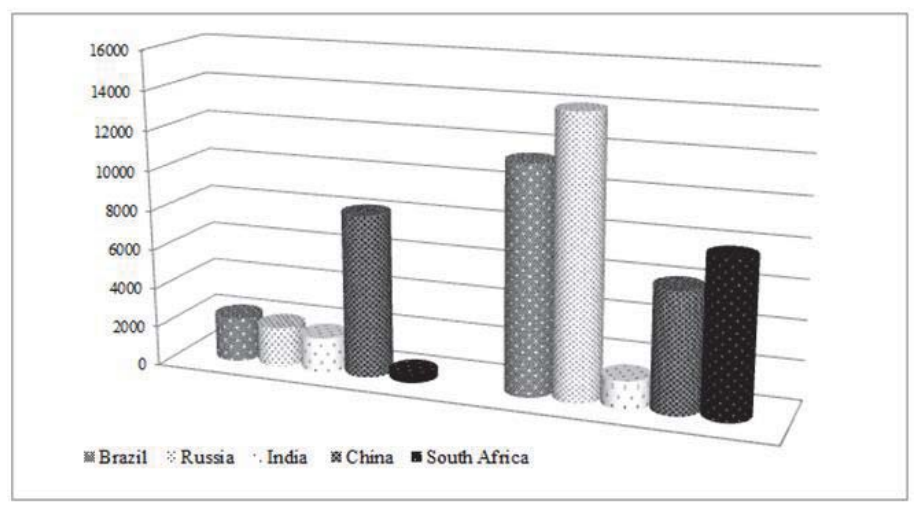

Source: BRICS (2013)

China is in its own class in respect of the size of the economy as measured through the GDP; and, per capita GDP statistics suggest that Brazil and Russia are far ahead of China. On the per capita GDP measure, even South Africa appears to be performing better that the fastest growing economy of the BRICS, China. Other than the global fame that the acronym thrust the set onto the global stage, the BRICS has quickly become an economically and politically "atheoretical" disposition and "spectre of irrelevance" (Mkandawire, 2011, p.3) in the contemporary international relations. The discrepancies in the BRICS set on the grounds of the economic size, which is one of the primary foundational lines of justifications for the conception of the grouping by Goldman Sachs proves to be problematic. Net export of goods and services demonstrates the health of the national economy because it refers to the exports of goods and services less imports, where exports include value of those sold and gratuitously "transferred by resident units to non-resident units", whereas imports include value of those purchased or gratuitously acquired by resident units from non-resident units" (BRICS, 2013, p.47). Russia's and China's performances on this measure for 2011/2012 are exceedingly higher than that for both Brazil and South Africa that are in deficit (Table 1).

Table 1: BRICS Set Net Export of Goods and Services (billion), 2011/2012

\begin{tabular}{|c|c|c|c|}
\hline Member State & $\mathbf{2 0 1 0}$ & $\mathbf{2 0 1 1}$ & $\mathbf{2 0 1 2}$ \\
\hline Brazil & -39 & -30 & -63 \\
\hline Russia & 3739.7 & 4776.5 & 4689.1 \\
\hline India & -22.3 & -22.3 & -32.63 \\
\hline China & 1510 & 1216 & 1448 \\
\hline South Africa & -5 & -18 & -18 \\
\hline
\end{tabular}

Source: BRICS (2013)

India did not publish this particular statistics; and, its values are estimated by the author on the basis of the current account data. However, it can be speculated that India would not possibly out-perform Russia or China. The point to make is that Russia and, to a significant degree, China do not deserve categorization as "emerging economies", hence there has been an ongoing insinuation that the BRICS describes a set of "strong emerging markets"; and, the latter would not fit South Africa, India and, perhaps, Brazil. Importantly, whereas the net export of goods and services have remained positive and/or improving for Russia and China between 2010 and 2012, deficits for Brazil, India and South Africa have commonly deteriorated and/or remained stagnant. Unsurprisingly, the national share of current account as percentage to GDP has remained in deficit for South Africa, Brazil and India whereas that for Brazil and China has been surplus (Figure 
3). This evidence once again dispels the myth of the five member states being a monolithic set of "emerging economies" or "strong emerging markets".

Figure 3: BRICS Set National Share of Current Account as Percentage to GDP, 2010-2012

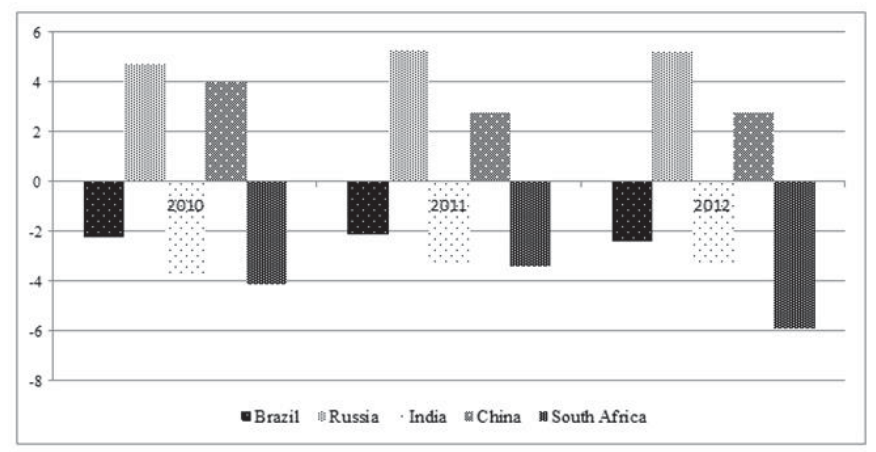

Source: BRICS (2013)

Russia is evidently in a league of its own while China is performing relatively better. Brazil, India and South Africa cannot even be classified as developing countries on account of these macro-economic indicators evidence. To this extent, the claim that the BRICs set was specifically framed on demographic, business, financial and economic rationale must be dismissed as irrational and illogical. In this context, there must be an underlying tenable interpretation of the emergence of the BRICs and BRICS in international relations. The ensuing section attempts to insinuate the motives underlying the conception and finding of the BRICS geopolitics in international relations.

\section{Geographic, Political and Economic Fissures and the BRICS Set Principles}

There are no macro-economic basis, at least on the face of the data analysed in this article, to justify why the original BRICs set was heralded as one of "the growth centres of the future with the potential to stimulate increased demand for a wide range of commodities" (Cairns \& Meilke, 2012, n.p). Evidently, the BRICS set consists of disparate states that cannot even be generalised as emerging markets or "strong emerging states". Apparently, the ongoing practice of the BRICS has nothing, other than the usurpation of the acronym, to do with the 2001 Goldman Sachs modelling. The June 2009 BRICs summit itself had revealed the depth fissures of the set in global geopolitics and discrepancies in their management of international relations (Cooper, 2009; Tandon \& Shome, 2009). The hope that the BRICS set could in 2050 dominate the global economy, relative to the G-6 of France, Germany, Italy, Japan, United Kingdom and the United States (Wilson \& Purushothaman, 2003; Wilson, Kelston \& Ahmed, 2010), must be dismissed as unrealistic. Besides, recent events in global geopolitics and management of international relations demonstrate that the BRICS set is neither the North Atlantic Treaty Organisation (NATO) nor EU nor the G-6 or G-7 or G-20 of the world. Five of the ten guiding principles (centrality of multilateralism on global issues; mutual respect for one another's choice of the development path; openness; non-bloc nature; and, neutrality with regard to third parties (BRICS, 2013) are such that the BRICS set would largely operate as a pluralistic jurisdiction and, therefore, a "non-places" regionalism in the global geopolitics and management of international relations. Indeed, the BRICS set is presently famous as an acronym but extraordinarily weak in global geopolitics and management of international relations. Rather than qualitatively alter the traditional global patterns of economics and politics, the BRICS set appears to be "striking for its declaratory than operational force" because the member states are more marked for their differences, dissimilar geographic locations, unique cultural and diverse historical contexts, rather than collective identities (Cooper, 2009, n.p.). For these reasons, the Standard and Poor Report does not recognize the BRICS set as a regional grouping (Tandom \& Shome, 2009). The BRICS set's hope of shaping the global geopolitics and management of international relations as a set is more sentimental than a potent operational pragmatic force. According to Cooper $(2009$, n.p),

"In many ways, nevertheless, the BRICs are more interesting for their differences than their similarities. Brazil and India are robust democracies. Russia is a managed democracy. China is a one party state. India has a fast rising population. Russia is in serious demographic trouble with a sharply reduced life expectancy. Brazil and Russia are resource rich. India and China are resource dependent". 
The business, financial and economic rationale of the BRICS set would not hold under these circumstances. It is impossible to ignore the Financial Times' (08 February 2006) observation to the effect that the "BRICs has joined nonplaces such as Emea, Asean and Nafta in the acronym-crazed geography of international management"; and, it stands as a nominal "rudimentary geographical trade configurations" (Olivier, 2001, p.43) in contemporary global geopolitics.

\section{BRICS Geopolitics: Groping in the Dark for "Non-places" Regionalism}

Comaroff \& Comaroff (1991, p.34 cited in Ndlovu-Gatsheni, 2007, p.176) advises that nuance globalism and regionalism formulations are at their heart a set of "historical anthropology of cultural confrontation ... of domination and reaction, struggle and innovation". The BRICS set does not escape this instructive cognitive theorization; and, the temptation to ascribe its implementation as an entirely "externally imposed discourse" (Mkadawire, 2011, p.1) must be resisted because Goldman Sachs' framing did not necessarily call for conventional regionalism nor the inclusion of South Africa. To a significant degree, the lexicon of globalism, regionalism and emerging economies or markets has come to add to the meta-narrative oxymorons of the calibre of development and developing countries. To this extent, the BRICS set's regionalism has to be suspected as a conceptual framing designed for privileging "certain forms of knowledge" by denigrating others (Mkandawire, 2011, p.6), but driven largely through governmentality in the global geopolitical relations. That is, the BRICS set has to be construed as a "non-regionalism" arrangement that harbours self-imaginary geopolitics in the management of international relations. Just like the struggles of coloniality and domination, globalism and regionalism of the BRICS set are, if we could borrow from Comaroff \& Comaroff (1991, p.34 cited in Ndlovu-Gatsheni, 2007, p.177), "purely ideological for they necessarily involved an effort to control the cultural terms by which the world was ordered and power legitimised". Indeed, each of the member states of the BRICS has unique cultures, histories and ideologies. Inevitably, there will be assimilation if the BRICS member states operate as a set in the international relations. According to Huggett \& Robinson (1996, p.159),

"... human societies evolved social and economic systems of relative complexity that allowed them both to consolidate within 'natural' boundaries and simultaneously to enlarge political control over non-contiguous territory. In the process of enlargement cultures inevitably came into conflict and out of this conflict they began slowly to homogenize. .... Larger and more powerful ones steadily extended their spheres of influence and control".

Reading from Bhabha (1994), though, contemporary fomentations of globalism and regionalism could as well be signifying hybridities that symbolise a space in the interface and a product of the blending of diverse cultures, histories and ideologies of the dominant power and the dominated, implying that initiatives such as the BRICS set could equally be a trail of "ambiguous legacies of invented traditions" (Ndlovu-Gatsheni, 2007, p.175).

Indeed, global geopolitics and international relations produce and reproduce the "political and economic landscape (that) presents a vulnerable picture" (Parsons, 2013, xv). There is a strong probability that the BRICS set joins the "noplaces" regionalism of coloniality that are reproduced and sustained "through a combination of violence, deceit, hypocrisy and lies" (Ndlovu-Gatsheni, 2013, p.11). In the contemporary world-economy, there are subverted continuities relating to processes and legacies of slavery, imperialism, colonialism and neo-colonial capitalism, wherein experiences of coloniality of being, power and knowledge are reinvented through nuance matrices (Grosfoguel, 2007; Maldonado-Torres, 2007; Ndlovu-Gatsheni, 2007, 2013; Gordon, 2011) of which the BRICS set could be typical. For most emerging economies, contemporary geopolitics and management of international relations involve complex processes of "intentionality", "irrationality" and "purposefulness", which do not necessarily destroy the global or regional status quo of being, power and knowledge (Grosfoguel, 2007; Maldonado-Torres, 2007; Ndlovu-Gatsheni, 2007, 2013; Gordon, 2011; Mkandawire, 2011). The notion of the universal replicability and desirability of market integration regionalism of the EU model as well as its developmental oxymoron of openness to trade (Mkandawire, 2011) must, therefore, be questioned and rejected. In the present era, as Ndlovu-Gatsheni (2013, p.11) asserts, regionalism as a suboptimal option for transition towards multilateralism and global openness is virtually normalised and universalised as "a natural state of the world"; and, this description appears to captivate the BRICS set's underlying business, financial and economic justification.

From the macro-economic indicators analysed in this article, it is evident that Russia and, to a lesser extent, China would consist of the more powerful cultures, histories and ideologies that could ultimately seek to influence and control the rest of the BRICS set. Huggett \& Robinson's (1996) observation is affirmed by the concept of coloniality, which is intricately connected to the nuance imperial paradigm, because it denotes "the spatio-temporal matrix" of power, knowledge and being (Maldonado-Torres, 2007; Ndlovu-Gatsheni, 2007). As Mkandawire (2011, p.19) puts it, "knowledge matters in development" and, by extension, it matters in the discourse and practice of globalism and regionalism. At best, globalism and regionalism in the BRICS set are deeply ambivalent, ambiguous and contradictory. 
Given that continuities and discontinuities created by ongoing articulation of new and old ideologies, the notion of coloniality draws meaning of contemporary global geopolitics and international relations from the "complex historical episodes" of the relations of "material phenomena and ideological controversies" (Marks, 1986 cited in Ndlovu-Gatsheni, 2007, p.176). The nuance imperial paradigm would suggest that Russia's and, to a lesser extent, China's motives and self-interests relating to the establishment of the BRICS involve self-imaginary geopolitics and "civilizing" missions. That is, the BRICS set's attempt at "homogenising thrust" and "compulsions of the market" that are "rechristened as globalisation", given the foundational principles and preconditions of the grouping, are a function of the contemporary global geopolitics and international relations where "emulation is a consequence of all human exchange" (Mkandawire, 2011, p.5). Inescapably, the BRICS set has to be interpreted as the emergence of inward-oriented imperial "civilizing" missions of the so-called "strong emerging states" racing to the bottom.

\section{Conclusion}

This article has argued that the BRICS is a complex and conflictual "non-places" set that is primarily externally-driven for inward-oriented management of international geopolitics of regionalism for states racing to the bottom through, among other things, the inherent potential for Russia and, perhaps, China to pursue "civilizing" missions that are steeped in their unique cultures, histories and ideologies. Disguised as fundamental universalistic truths, neoliberal globalism, market integration regionalism and the EU model have been touted as benign and inescapable options for the management of contemporary global geopolitics and international relations. Based on the customs union theory, the EU has been construed as the ideal model of amalgamation of jurisdiction that would deliver collective prosperity and development. Developing countries' regionalism thinking has, however, flagrantly circumvented the preconditions for complementarity of economies as well as production and trade structures. Whereas the BRICS describes itself as "a group of leading emerging economies playing a key role in the world development platforms" (BRICS, 2013, vi), its performance on the global stage as a set does not seem to affirm the self-description as "strong emerging states", economically and politically, except for Russia.

From the macro-economic data presented in this article, the BRICS set consists of disparate states that cannot even be generalised as emerging markets or "strong emerging states". Apparently, the ongoing practice of the BRICS has nothing, other than the usurpation of the acronym, to do with the 2001 Goldman Sachs modelling. The hope that the BRICS set could in 2050 dominate the global economy, relative to the G-6 of France, Germany, Italy, Japan, United Kingdom and the United States, is dismissed as unrealistic. Also, recent events in the contemporary global geopolitics and management of international relations demonstrate that the BRICS set is neither the NATO nor EU nor the G-6 or G7 or G-20 of the world. Five of the ten guiding principles are such that the BRICS set would largely operate as on pluralistic jurisdiction and, therefore, deteriorate into "non-places" regionalism in the global geopolitics and management of international relations. This article concedes that rather than qualitatively alter the traditional global patterns of economics and politics, the BRICS set appears to be "striking for its declaratory than operational force" because the member states are more marked for their differences, dissimilar geographic locations, unique cultural and diverse historical contexts, rather than collective identities. The BRICS set's hope of shaping the global geopolitics and management of international relations as a set is more sentimental than a potent operational pragmatic force. Equally, the business, financial and economic rationale of the BRICS set do not hold because member states are more prominent for their uniqueness and differentness, especially Russia and, perhaps, China that are scarcely emerging economies. The Financial Times' (08 February 2006) observation to the effect that the "BRICs has joined non-places such as Emea, Asean and Nafta in the acronym-crazed geography of international management" is instructive. This article accepts that the BRICS stands as a nominal constellation in contemporary global geopolitics and international relations. The article concludes that the BRICS set will remain a disparate and non-cohesive grouping, both economically and politically, because member states have opted for pluralistic jurisdiction, non-unison global action and non-conformity to notions of regionalism. For these reasons, the BRICS set has to be construed as nominal rudimentary "non-regionalism" grouping and "inexact" imitation, deliberate or accidental, in the management of contemporary global geopolitics and international relations.

\section{References}

Bachmann, V. \& Sidaway, J.D. 2010. African regional integration and European involvement: external agents in the East African Community. South African Geographical Journal, 92(1), 1-6.

Bell, H.A. (2011). Status of the "BRICs": An analysis of growth factors. International Research Journal of Finance and Economics, 69, 
19-25.

Bhadha, H. (1994). The Location of Culture. London: Routledge.

Boas, M. (2003). Weak states, strong regimes: towards a "real" political economy of African regionalisation. In J.A. Grant \& F. Soderbaum (Eds.), The New Regionalism in Africa. Aldershot: Ashgate.

BRICS, (2013). BRICS Joint Statistical Publication, 2013. Durban: BRICS.

Cairns, A. \& Meilke, K.D. (2012). The Next-11 and the BRICs: are they the future markets for agrifood trade? Canadian Agricultural Trade Policy Research Network (CATPRN) Working Paper 2012-03, April 2012, Ontario: CATPRN.

Cooper, A.F. (2009). Picking your club: G8 or G20, BRICs or B(R)ICSAM? Keynote Presentation at the BRICSAM and the Fight against Global Poverty, Organised by the Oxfam International, Geneva, July 13, 2009.

Davies, R. (1996). Promoting regional integration in Southern Africa: an analysis of prospects and problems from a South African perspective. African Security Review, 5, 27-38.

Fawcett, L. (2005). Regionalism from a historical perspective. In M. Farrell, B. Hettne \& L. van Langenhove (Eds.), Global Politics of Regionalism: Theory and Practice. London: Pluto Press.

Gibb, R. (2007). Regional integration in post-apartheid South Africa. Tijdschriftvoor Economische en Sociele Geografie, 98(4), $421-435$.

Gibb, R. (2009). Regional integration and Africa's development trajectory: meta-theories, expectations and reality. Third World Quarterly, 30(4), 701-721.

Glemarec, Y. \& Puppim de Oliviera, J.A. (2012). The role of the visible hand of public institutions in creating a sustainable future. Public Administration and Development, 32, 200-214.

Gordon, L.R. (2011). Shifting the Geography of Reason in an Age of Disciplinary Decadence Transmodernity, Fall, 95-103.

Grant, J.A. \& Soderbaum, F. (Eds.) (2003). The New Regionalism in Africa. Aldershot: Ashgate.

Grosfoguel, R. 2007. The epistemic decolonial turn. Cultural Studies, 21(2-3), 211-223.

Haq, Z. \& Meilke, K. (2009a). Do BRICs and emerging markets differ in their agrifood trade? Paper presented at the International Association of Agricultural Economists Conference, Beijing, China, August 16-22, 2009.

Haq, Z. \& Meilke, K. (2009b). The role of income growth in emerging markets and the BRICs in agrifood trade. Canadian Agricultural Trade Policy Research Network (CATPRN) Working Paper 2009-02, February 2009, Ontario: CATPRN.

Hettne, B. (1999). Globalization and the new regionalism of the second great transformation. In B. Hettne, A. Inotai \& O. Sunkel (Eds.), Globalism and the New Regionalism, Volume 1. London: Macmillan.

Huggett, R. \& Robinson, M. (1996). Introduction. In I. Douglas, R. Huggett \& M. Robinson (Eds.), Companion Encyclopedia of Geography: The Environment and Humankind (pp.159-161). London: Routledge.

Iheduru, O. (2003). New regionalism, states and non-state actors in West Africa. In R. Grant \& F. Soderbaum (Eds.), The New Regionalism in Africa. Aldershot: Ashgate.

Lee, M.C. (2003). The Political Economy of Regionalism in Southern Africa. London: Boulder.

Maldonado-Torres, N. (2007). On the coloniality of being. Cultural Studies, 21(2-3), 240-270.

Mistry, P. (2000). Africa's record of regional cooperation and integration. African Affairs, 99(937), 553-573.

Mkandawire, T. (2011). Running while others walk: knowledge and the challenge of Africa's development. Africa Development, 36(2), 136.

Ndlovu-Gatsheni, S.J. (2007). Re-thinking the colonial encounter in Zimbabwe in the early twentieth century. Journal of Southern African Studies, 33(1), 173-191.

Ndlovu-Gatsheni, S.J. (2013). Why decoloniality in the 21st century? The Thinkers, 48, 10-15.

Njinkeu, D. \& B.P. Fosso (2006). Intra-African trade and regional integration. (Online) Available:http://www.afdb.org/pls/portal/url/ ITEM/22FF70E5AF17BA12E040C00AOC3D33E9 (October 22, 2010).

Oden, B. (1999). New regionalism in Southern Africa: part of or alternative to the globalisation of the world economy? In: B. Hettne, A. Inotai \& O. Sunkel (Eds.), Globalism and the New Regionalism, Vol. 1. London: Macmillan.

Olanrewaju, S.A. (2007). Aid for Trade: Prospects for Enhancing African Trade Capacity. (Online) Available:

http://www.afdb.org/pls/portal/url/ITEM/3DA174D19ADB3C0FE040C00A0C3D5277 (November 10, 2008).

Olivier, G. (2001). Regional integration and African revival. Africa Insight, 31(3), 39-46.

Oyejide, T.A. (2000). Policies for Regional Integration in Africa. Economic Research Papers No. 62. (Online) Available: http://www.afdb.org/pls/portal/url/ITEM/F5411BA3504F7686E030ABC0668C622B (November 10, 2008).

Parsons, R. (2013). ZUMANOMICS Revisited: The Road from Mangaung to 2030. Sunnyside: Jacana.

Ralinala, R.M. (2004). The Economic Community of West African States. In P. Hugo \& E. Maloka (Eds.), The State of Africa 2003-04: A Thematic and Factual Review (pp.130-134). Pretoria: AISA.

Ramutsindela, M. (2005). Perspectives on regionalism in (southern) Africa. GeoJournal, 62, 107-110.

Ramutsindela, M. (2009). Gaddafi, continentalism and sovereignty in Africa. South African Geographical Journal, 91(1), 1-3.

Ramutsindela, M. (2010). Editorial: the SAGJ and 2010. South African Geographical Journal, 92(2), 91-95.

Ramutsindela, M. (2011). Southern Africa: the geopolitical configuration of lived regions. Political Geography, doi:1016/j.polgeo. 2011.04.001.

Sidaway, J.D. (1998). The (geo)politics of regional integration: the example of the Southern African Development Community? Environment and Planning D: Society and Space, 16, 549-576.

Sidaway, J.D. (2002). Imagined Regional Communities: Integration and Sovereignty in the Global South. London: Routledge.

Sidaway, J.D. \& Gibb, R. (1998). SADC, COMESA and SACU: contradictory formats for regional integration in southern Africa. In D. 
Simon (Ed.), South Africa in Southern Africa: Reconfiguring the Region. London: James Currey.

Simon, D. (1998). Introduction: shedding the past, shaping the future. In D. Simon, (Ed.), South Africa in Southern Africa: Reconfiguring the Region. London: James Currey.

Simon, D. (2010). The changing context for regional integration in southern Africa: how adaptive are its regional institutions? South African Geographical Journal, 92(2), 96-104.

Tandon, S. \& Shome, S. (2009). The cracks in the BRICs. Annals of the University of Petrosani, Economics, 9(4), 273-282.

Taylor, I. (2005). Nepad: Towards Africa's Development or Another False Start? London: Lynn Rienner.

Todaro, M.P. (1997). Economic Development. London: Longman.

Wilson, D., Kelston, A.L. \& Ahmed, S. (2010). Is this the "BRICs decade?" BRICs Monthly, 10(3). New York: Goldman Sachs.

Wilson, D. \& Purushothaman, R. (2003). Dreaming with BRICs: the Path to 2050. Global Paper 99, October 2003, New York: Goldman Sachs. 